\title{
Performance of a 10-Year Constructed Mangrove Wetland for Wastewater Treatment
}

\author{
Nora Fung-Yee Tam ${ }^{1}$, Ting-Ting Tin ${ }^{2}$, Yuk-Shan Wong ${ }^{3}$ \\ ${ }^{1}$ City University of Hong Kong, Kowloon \\ Hong Kong, China \\ bhntam@cityu.edu.hk \\ ${ }^{2}$ Futian-CityU Mangrove Research and Development Centre, City University of Hong Kong \\ Kowloon, Hong Kong, China \\ kesi1234@sina.com \\ ${ }^{3}$ Open University of Hong Kong \\ Kowloon, Hong Kong, China \\ yswong@ouhk.edu.hk
}

\section{Extended Abstract}

Waste water pollution is a serious environmental problem in urbanized and industrialized cities, particularly in Pearl River Delta, South China because of its repaid economic development. Although different wastewater treatment technologies, such as activated sludge process, membrane bioreactors and membrane separation, have been developed for water pollution control, they are often expensive with high capital and operation costs. The treatment systems are also complicate to operate. Constructed wetlands (CWs), which mimic natural wetland systems, can improve water quality through the combined actions of microorganisms, plants and substrate. Because of their low operation costs and easy operation, CWs have been used for wastewater treatment for decades, especially in rural areas [1]. However, most of these systems use annual herbaceous plant species that require frequent harvesting and maintenance [2], very few employ perennial woody plants such as mangroves. Mangroves, unique and woody perennial plant communities distributed along tropical and subtropical coastlines, are specially adapted to stressful environments, including high salinity, waterlogging, alternating aerobic and anaerobic conditions, unstable substratum and even toxic pollutants [3]. Although it is well known that mangroves sequester organic carbon and nutrients, the feasibility of using constructed mangrove wetlands for treating municipal wastewater that may contain toxic compounds is still uncertain. Limited studies demonstrate the potential efficiency of mangrove wetlands in removing nutrients and toxic pollutants in wastewater, but the results were limited to the short-term, small-scale bench-type constructed mangrove system [4]. Similar to other CWs, there is a lack of knowledge about the long-term effectiveness and treatment performance of constructed mangrove wetlands for municipal wastewater. This study therefore aims to evaluate the performance of a 10-year pilot constructed mangrove wetland system for treating municipal sewage and the feasibility of its long-term use. In this study, the treatment efficiency between belts planted with Aegiceras corniculatum and Kandelia obovata, the two dominant mangrove species in South China, was also compared.

The results indicated that the constructed mangrove wetland system, irrespective of plant species, maintained a steady and efficient treatment performance throughout its 10-year operation. There was no need to do any mowing, harvesting or replanting of the individuals in the past 10 years, indicating that the constructed mangrove wetland system required minimal maintenance and was easy to operate. The removal of biological oxygen demand (BOD) was generally steady throughout the operation period, but the reduction of total nitrogen (TN) and total phosphorus (TP) varied with operation time. The removal of TN and TP increased as plants continued to grow, but the removal rate began to decline toward the latter part of the operation when plants became mature. These results showed that the removal of these two nutrients was closely related to plant growth, and the removal percentages in this system varied among pollutants. On average, the mean removal percentages of suspended solids, BOD, TN and TP in the municipal sewage collected from surrounding premises over the experimental period were $70.2 \%, 70.9 \%, 65.8 \%$ and $62.6 \%$, respectively. These values were comparable to other CWs reported in literature. 
The two mangrove species had comparable treatment efficiencies for BOD and TN, but the removal of TP was significantly higher and steadier in the belt planted with $A$. corniculatum than with $K$. obovata. During the operation period, plants continued to grow from seedlings to mature adults with flowers and droppers produced years after years, indicating that both species could tolerate the continuous discharge of municipal sewage. To our knowledge, this is the first study to demonstrate that a horizontal subsurface flow constructed mangrove wetland achieved a steady and effective treatment performance over a 10-year period without the need for maintenance, and provided sustainable long-term removal of organic matter and nutrients (especially nitrogen) in municipal sewage.

\section{References}

[1] J. Vymazal, "Long-term performance of constructed wetlands with horizontal sub-surface flow: Ten case studies from the Czech Republic," Ecol. Eng., vol. 37, pp. 54-63, 2011.

[2] H. Wu, J. Zhang, H. H. Ngo, W. Guo, Z. Hu, S. Liang, "A review on the sustainability of constructed wetlands for wastewater treatment: Design and operation," Biores. Technol., vol. 175, pp. 594-602, 2015.

[3] J. Y. S. Leung, Q. Cai Q, N. F. Y. Tam, "Comparing subsurface flow constructed wetlands with mangrove plants and freshwater wetland plants for removing nutrients and toxic pollutants," Ecol. Eng., vol. 95, pp. 129-137, 2016.

[4] Y. Wu, A. Chung, N. F. Y. Tam, N. Pi, M. H. Wong, "Constructed mangrove wetland as secondary treatment system for municipal wastewater," Ecol. Eng., vol. 34, pp. 137-146, 2008. 